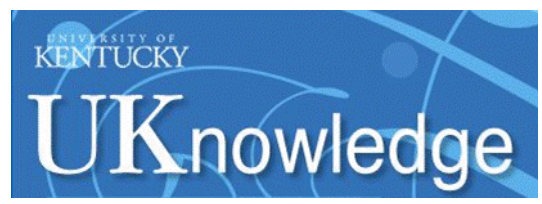

University of Kentucky

UKnowledge

$1-26-2017$

\title{
Subjective Outcome Evaluation of the Community-Based P.A.T.H.S. Project: Views of Program Implementers
}

\author{
Daniel T. L. Shek \\ University of Kentucky \\ Janet T. Y. Leung \\ The Hong Kong Polytechnic University, China \\ Cecilia M. S. Ma \\ The Hong Kong Polytechnic University, China \\ Jing Wu \\ The Hong Kong Polytechnic University, China
}

Follow this and additional works at: https://uknowledge.uky.edu/pediatrics_facpub

Part of the Chinese Studies Commons, Community-Based Learning Commons, and the Developmental Psychology Commons

Right click to open a feedback form in a new tab to let us know how this document benefits you.

\section{Repository Citation}

Shek, Daniel T. L.; Leung, Janet T. Y.; Ma, Cecilia M. S.; and Wu, Jing, "Subjective Outcome Evaluation of the Community-Based P.A.T.H.S. Project: Views of Program Implementers" (2017). Pediatrics Faculty Publications. 286.

https://uknowledge.uky.edu/pediatrics_facpub/286

This Article is brought to you for free and open access by the Pediatrics at UKnowledge. It has been accepted for inclusion in Pediatrics Faculty Publications by an authorized administrator of UKnowledge. For more information, please contact UKnowledge@lsv.uky.edu. 


\section{Subjective Outcome Evaluation of the Community-Based P.A.T.H.S. Project: Views of Program Implementers}

\section{Digital Object Identifier (DOI)}

https://doi.org/10.1515/ijdhd-2017-7008

\section{Notes/Citation Information}

Published in International Journal on Disability and Human Development, v. 16, issue 4, p. 395-405.

(C2017 Walter de Gruyter GmbH, Berlin/Boston.

The copyright holder has granted the permission for posting the article here. 
Daniel T.L. Shek*, Janet T.Y. Leung, Cecilia M.S. Ma and Jing Wu

\section{Subjective outcome evaluation of the community- based P.A.T.H.S Project: views of program implementers}

DOI 10.1515/ijdhd-2017-7008

Received July 22, 2016; accepted August 22, 2016; previously published online January 26, 2017

\begin{abstract}
The present study adopted subjective outcome evaluation to examine program effectiveness from the views of implementers $(\mathrm{N}=375)$ who implemented the community-based Tier 2 Program of the Project P.A.T.H.S. in Hong Kong. The results revealed that most of the program implementers were satisfied with the program content, their own performance, and program benefits. In agreement with previous studies, the satisfaction ratings of both program content and implementer performance positively predicted perceived program benefits. Regarding the influences of different program delivery approaches, programs with the "interest-enhancement" (INT) element received a more positive evaluation from implementers than did the programs without that element. For programs with the "work-related" (WORK) element, parental involvement significantly raised implementers' satisfaction ratings on their own performance. The current findings provided evidence for the effectiveness of the P.A.T.H.S. Tier 2 Program from the perspective of the implementers.
\end{abstract}

Keywords: at-risk adolescents; Chinese adolescents; positive youth development; Project P.A.T.H.S.; subjective outcome evaluation.

\footnotetext{
*Corresponding author: Daniel T.L. Shek, Associate Vice President (Undergraduate Program) and Chair Professor of Applied Social Sciences, Department of Applied Social Sciences, The Hong Kong Polytechnic University, Hunghom, Hong Kong, P.R. China; Centre for Innovative Programmes for Adolescents and Families, The Hong Kong Polytechnic University, Hong Kong, P.R. China; Department of Social Work, East China Normal University, Shanghai, P.R. China; Kiang Wu Nursing College of Macau, Macau, P.R. China; and Division of Adolescent Medicine, Department of Pediatrics, Kentucky Children's Hospital, University of Kentucky School of Medicine, Lexington, KY, USA, E-mail: daniel.shek@polyu.edu.hk Janet T.Y. Leung, Cecilia M.S. Ma and Jing Wu: Department of Applied Social Sciences, The Hong Kong Polytechnic University, Hong Kong, P.R. China
}

\section{Introduction}

Adolescence has been widely considered as a risky developmental period marked by the emergence and escalation of problematic behaviors, such as substance abuse, selfharm and suicide, and unhealthy lifestyles [1, 2]. In Hong Kong, adolescent developmental issues such as mental health problems deserve public concern [3, 4]. Shek [5] pointed out that for adolescents in Hong Kong nowadays, substance abuse, shoplifting, mental health problems, underage sex, and youth unemployment are all growing problems. Besides, family and parenting problems are common issues in families with adolescent members [5]. The prevalence of adolescent developmental issues is an alarm for the current and future society development of Hong Kong. Hence, there is an urgent need to prevent and reduce adolescent risk behavior.

Traditional problem-based adolescent prevention interventions were designed according to specific developmental problems. For example, the "Alcohol treatment targeting adolescents in need (ATTAIN)" Project was established to cognitively and behaviorally reduce alcohol and marijuana use among minority juvenile offenders in the US [6]. However, there are many criticisms of such a "problem-based" approach. First, most of the problembased interventions had unsatisfactory long-term effects $[7,8]$. Secondly, it is redundant and not practical to develop prevention programs for each specific adolescent developmental issue because of the correlated nature of problematic behaviors [5]. Lastly, over-emphasis on adolescent "problems" and "weaknesses" may stigmatize adolescents.

In the past several decades, the strength-based approach has emerged to overcome the shortcomings of the traditional paradigm [9]. Martin Seligman stated that "Psychology is not just the study of weakness and damage; it is also the study of strength and virtue. Treatment is not just fixing what is broken; it is nurturing what is best within ourselves" [10, p. 4]. The strength-based approach emphasizes integrated youth development from an ecological perspective. It is argued that young people would be less likely to engage in risk behaviors if they 
acquire psychosocial competencies [11]. With specific reference to the Hong Kong context, the Project "P.A.T.H.S. (Positive Adolescent Training through Holistic Social Programs)" that has been launched since the 2005/2006 school year is a good example of the positive youth development approach.

Funded by the Hong Kong Jockey Club Charities Trust (HKJCCT), the P.A.T.H.S. Project was initiated with the collaboration of the Education Bureau, Social Welfare Department, and a research team comprising academics from five universities in Hong Kong. The P.A.T.H.S. Project has received overwhelmingly positive feedback during its first-stage of implementation [12, 13]. Different stakeholders held positive views on the effectiveness of the program. Hence, the project was extended for another cycle for the participating schools to consolidate the implementation experience. Therefore, till the 2011/2012 school year, the project had been implemented on the basis of school contexts for 7 years. To draw an all-around picture of the P.A.T.H.S. Project, process evaluation and outcome evaluation are the two basic forms used to evaluate the effectiveness of the programs. Given that the implementation process refers to program adherence, program receiver's engagement, goal attainment, and process-outcome linkage [14, 15], process evaluation methods including interim evaluation [16] and systematic management information collection based on a co-walker scheme [17] were adopted in evaluating the P.A.T.H.S. Project. On the other hand, objective and subjective outcome evaluation methods were employed to focus on answering questions like whether or not the intended program goals and objectives have been met, as well as whether or not the program is effective and efficient [18]. The existing evaluation studies have verified the success of the school-based programs by revealing high implementation quality, less problematic behaviors and enhanced positive psychosocial constructs in student participants, and high satisfaction ratings from different stakeholders [19-21].

However, researchers have found that clinical and community-based programs are more effective in changing specific behaviors than school-based programs [22]. For example, Franklin and Corcoran reviewed the programs and practices for preventing adolescent pregnancy [23]. They found that community-based programs (such as family planning clinics and girls clubs) were more efficient in reducing the pregnancy rates than school-based programs. Therefore, to further promote the P.A.T.H.S. Project in the community context, the third phase of the project implementation was formally started in 2013. During the third phase of implementation, communitybased youth enhancement programs were developed and implemented by social workers in non-governmental organizations (NGOs), who also collaborated with school teachers [24]. In the first 2 years of community-based program implementation, existing studies showed that the community-based P.A.T.H.S. Projects were as effective as the school-based ones [25-28]. Therefore, the present study attempted to replicate these findings in the third year implementation of community-based P.A.T.H.S. Project and to find out the factors influencing the effectiveness of the programs.

Two tiers of programs are included in the P.A.T.H.S. Project targeting different types of adolescents. The Tier 1 Program is a curricula-based program attempting to promote the development of all junior secondary school students in Hong Kong. On the other hand, Tier 2 Program targets students with greater psychosocial needs in behavioral, emotional, or social domains that take up nearly one-fifth of the population [19]. Adopting the subjective outcome evaluation method, the present study focused on the effectiveness of the Tier 2 Program implemented in the year 2015.

One of the important features of outcome evaluation is that it could assess the perceptions and satisfaction levels of various important stakeholders [29]. There is a consensus in the evaluation literature about the importance of involving views of multiple stakeholders, such as program receivers, program implementers, evaluators, and parents if the receivers are children [30-32]. However, there is a research gap that most empirical studies have been devoted to understanding the program participants' views and neglected the views of other stakeholders [33]. There are several justifications for including the views of implementers in the Tier 2 Program. First, data based on different stakeholders tend to be more objective because it could achieve triangulation and avoid single-rater bias [34]. Secondly, amongst all stakeholders, program implementers have the most first-hand information about how the program had been delivered, how the receivers reacted, and how the implementers themselves performed [35]. Thirdly, evaluating program quality based on the implementers' perspective shows respect to the frontline professionals and provides them with opportunities to have self-reflection [33]. Therefore, implementers' perceptions of the Tier 2 Program would be evaluated in the current study.

To find out the factors influencing the effectiveness of the Tier 2 Program, two important aspects would be considered in the present study. First, while different approaches can be used in implementing the Tier 2 Program, four types of approaches are most commonly employed. These included: (a) adventure-based counseling approach 
(ABC), (b) volunteer training and service (VTS) such as volunteerism, (c) work-related (WORK) approach such as visiting workplaces and skills development, and (d) interest-enhancement (INT) approach such as flower arrangement learning course. A combination of two or more types of approaches is also common in implementing the Tier 2 Programs.

The ABC and VTS approaches were both developed on the basis of experiential learning theory. "ABC" is an experiential counseling technique that focuses on adolescents' group cooperation and interpersonal skills [36, 37]. Activities adopting the $\mathrm{ABC}$ element help increase student participants' self-esteem and strengthen their social maturity in a group-counseling environment [38-40]. "VTS" activities also have positive influences on adolescents' social development [41]. Stressing on a "non-obligated" helping [42], volunteerism is conducive to promoting prosocial attitudes and reducing problematic behaviors in adolescents [43]. Previous studies have consistently revealed the benefits of these two approaches [20,21]. Shek, Yu, and Ho [20] compared participants' ratings of the programs with different delivery modes and found that programs incorporating both $\mathrm{ABC}$ and VTS elements were more effective than programs incorporating solely ABC, solely VTS, or other delivery approaches [25]. However, "WORK" and "INT" activities also benefit adolescents' development practically. As for the importance of "WORK" element, Whiston and Quinby [44] reviewed several school counseling programs and concluded that career-related programs effectively promoted students' vocational identity, self-understanding, and the skills of connecting abilities with career choices. Regarding the "INT" element, empirical studies showed that engaging in constructive extracurricular activities such as basketball or marching band promoted adolescents' school achievement and decreased their risky behaviors in the long run [45]. Hence, interest enhancement activities are able to trigger the intrinsic motivation of the adolescents as a motivational strategy [46]. Very few studies were concerned about the importance and effectiveness of the "WORK" and "INT" delivery approaches in the past. Accordingly, in the present study, WORK and INT in addition to VTS and ABC were taken into consideration to explore the effectiveness of different delivery approaches.

Apart from diverse approaches, the community-based Tier 2 Programs were also different amongst themselves with respect to parental involvement. For some programs, only students with greater psychosocial needs participated in the activities. However, in some other programs, parent(s) were also involved. Some past studies have examined the effect of parental involvement and home-school relationship on adolescents' academic performance (e.g. 47, 48). Effective parental involvement in students' education not only strengthens children and adolescents' academic achievement and self-regulatory skills [49] but also promotes teachers' teaching efficacy and parents' own personal efficacy [50]. However, possible barriers to the cooperation between parents and teachers also exist. For parents, they may have inadequate skills without proper instructions. For teachers, they have to face the uncertainty when dealing with diverse families [48]. Although the importance of parental involvement in adolescents' education has been well acknowledged, the effectiveness of parental involvement in positive youth development programs has seldom been considered in previous studies. Hence, the current study would try to fill this research gap.

Based on the aforementioned background, the present study evaluated the effectiveness of the Tier 2 Program of P.A.T.H.S. Project in Hong Kong in the year 2015 based on the program implementers' views. Several research questions to be addressed and hypotheses to be examined in the present study are listed as follows:

1. How satisfied were the program implementers regarding the program content, their performance, and program benefits? As the previous studies steadily demonstrated positive feedback from the program implementers [21, 28], we hypothesized that program implementers would have a positive evaluation of the program content (Hypothesis 1a), implementer performance (Hypothesis 1b), and program benefits (Hypothesis 1c).

2. What are the inter-relationships amongst the ratings of program content, implementer quality, and program benefits? Based on previous findings, it was hypothesized that satisfaction ratings of the three aspects would be significantly associated with each other (Hypotheses 2a, 2b, and 2c). Furthermore, we hypothesized that satisfaction ratings of program content (Hypothesis 2d) and implementer quality (Hypothesis 2e) would both significantly predict that of program effectiveness.

3. Do grade differences exist when the program implementers appraise the program content, implementer quality, and program benefits? Grade differences were found in the Tier 1 Program from the perspective of implementers (e.g. 24), with lower-grade teachers perceived higher program effectiveness and their own performance than did higher-grade teachers. However, grade differences among implementers in the Tier 2 Program were seldom found [27, 28]. Hence, using the findings based on the Tier 1 Program, we 
expected there would be grade differences (Hypothesis 3).

4. How would different delivery modes affect implementers' satisfaction ratings of the programs? Based on the findings of previous studies [28], we hypothesized that the ABC/VTS/WORK/INT elements would have positive influences on the effectiveness of the programs (Hypothesis 4).

5. How would parental involvement influence implementers' perceived program effectiveness? A few previous studies have implied the positive impacts of involving teachers or parents $[47,48]$. Based on these findings, we hypothesized that programs involving parent(s) would receive a more positive evaluation from the implementers than did programs not involving parent(s) (Hypothesis 5).

\section{Methods}

To understand the perceptions of implementers toward the program, researchers from the Project P.A.T.H.S. invited the implementers to complete a Subjective Outcome Evaluation Form for Instructors (Form D). It is a self-administrated questionnaire with clear guidelines and instructions. In the third year of implementation, we received 375 completed questionnaires, with nine questionnaires with unclear information on the grade of the students.

\section{Instruments}

The Subjective Outcome Evaluation Form for Implementers (Form D) was employed at the end of the program. This measure covers three parts, which include (a) instructors' views on the program, (b) instructors' views on themselves, and (c) instructors' perceived benefits of the program on the participants. Moreover, to collect additional comments from implementers, another four open-ended questions were also used to understand “(a) important thing(s) the instructors have learned in the program, (b) thing(s) that the instructors appreciate the most in the program, (c) difficulties the instructors encountered, and (d) areas of the program that need to be improved". In the present study, only the structured items were analyzed and reported. All structured items were assessed with items on a 6-point scale (from "strongly disagree" to "strongly agree").

Besides, additional information about the program was collected from the program implementers. Research assistants assisted to categorize the program delivery approaches according to the activities the NGOs conducted. On the other hand, types and number of participants for every program were also collected.

\section{Data analyses}

The basic units of analysis were individual data of the implementers in the current study. SPSS for Windows, version 23.0 (IBM-SPSS Inc,
Chicago, IL, USA) was used to generate all statistical analyses. First, the characteristics of the Tier 2 Program (delivery approach and types of participants) were categorized. Then, percentages of responses of the implementers regarding their views on the program (i.e. program qualities, program implementer qualities, and program benefits) were analyzed by descriptive statistics to test Hypotheses 1a-1c. Moreover, the relationships among the above three areas were examined by Pearson correlation and multiple regression analyses to test Hypotheses 2a-2e. To explore grade differences of implementers' subjective outcome evaluation (Hypothesis 3), a multivariate analysis of variance (MANOVA) was conducted using the evaluation of three aspects (i.e. program content, implementer performance, and program benefits) as dependent variables.

To investigate the influences of different delivery approaches and parental involvement on perceived program effectiveness, we first recoded the program approaches into four dichotomous variables for data analysis. For each of the four program approach variables (i.e. ABC, VTS, WORK, and INT), if the corresponding element was adopted in the program, the variable was coded as "1", otherwise, it was coded as " 0 ". Almost all programs adopted a combination of two or more elements. Likewise, the "parental involvement" variable was also coded according to the types of participants. Specifically, programs that included parent(s) in the activities were coded as " 1 " for the "parental involvement" variable, while those without parental involvement coded as " 0 ". To test Hypotheses 4 and 5, a series of ANOVA analyses were also performed with the three subjective outcome evaluation aspects (i.e. program content, implementers, and benefits) as dependent variables, and the four program approaches (ABC, VTS, WORK, and INT) as well as parental involvement as independent variables.

\section{Results}

In the year 2015, a total of 21 NGOs conducted 41 projects of the P.A.T.H.S. Tier 2 Programs. Most of the projects adopted more than one delivery approach. For example, 22 projects $(\mathrm{N}=189)$ adopted the "ABC", "VTS", and "INT" elements at the same time, while eight projects $(\mathrm{N}=59)$ combined the four elements simultaneously. As demonstrated in Table 1, among all, the "ABC" element was the most frequently used $(n=40)$, followed by the "VTS" $(n=39)$, and "INT" ( $n=32)$ elements. The "WORK" element was also adopted by several projects $(n=11)$. Besides the commonly adopted four approaches, parent(s) were actively involved in 12 projects.

As shown in Table 2, all of the three rating scales showed good internal consistency $(\alpha=0.89-0.91)$. Cronbach's $\alpha$ coefficient of the overall scale was 0.94 , suggesting that the scales are reliable.

The results of the descriptive data analysis showed that the program implementers were highly satisfied with the program content (Table 3). Almost all implementers agreed that "the quality of the service was high" (99.2\%) and "on the whole, I am satisfied with the service 
Table 1: Summary of the characteristics and effectiveness of the Tier 2 Programs.

\begin{tabular}{|c|c|c|c|c|c|c|}
\hline $\begin{array}{l}\text { Program } \\
\text { approach }^{\mathrm{a}}\end{array}$ & $\begin{array}{l}\text { Parental } \\
\text { involvement }\end{array}$ & $\begin{array}{l}\text { Average number of } \\
\text { student participants }\end{array}$ & $\begin{array}{l}\text { Average number of } \\
\text { parent participants }\end{array}$ & $\begin{array}{l}\text { Average number of } \\
\text { teacher participants }\end{array}$ & $\begin{array}{r}\text { Average program } \\
\text { attendance (\%) }\end{array}$ & $\begin{array}{r}\text { Mean of overall } \\
\text { effectiveness (M, SD) }\end{array}$ \\
\hline \multirow[t]{3}{*}{$A B C$} & $\begin{array}{l}\text { Yes }(n=12, \\
N=95)\end{array}$ & 129.8 & 31.2 & 11.9 & 87.75 & $(5.07,0.35)$ \\
\hline & $\begin{array}{l}\text { No }(n=30 \\
N=260)\end{array}$ & 88.0 & $\mathrm{~N} / \mathrm{A}$ & 8.3 & 84.62 & $(4.99,0.40)$ \\
\hline & $\begin{array}{l}\text { Total }(\mathrm{n}=40, \\
\mathrm{N}=355)\end{array}$ & 99.3 & 8.4 & 9.3 & 85.46 & $(5.01,0.39)$ \\
\hline \multirow[t]{3}{*}{ VTS } & $\begin{array}{l}\text { Yes }(n=11 \\
N=92)\end{array}$ & 131.7 & 31.8 & 12.1 & 87.81 & $(5.07,0.35)$ \\
\hline & $\begin{array}{l}\text { No }(n=29, \\
N=250)\end{array}$ & 86.1 & 0.0 & 7.8 & 84.48 & $(4.98,0.42)$ \\
\hline & $\begin{array}{l}\text { Total }(\mathrm{n}=39, \\
\mathrm{N}=342)\end{array}$ & 98.6 & 8.7 & 9.0 & 85.39 & $(5.01,0.40)$ \\
\hline \multirow[t]{3}{*}{ WORK } & $\begin{array}{l}\text { Yes }(n=3, \\
N=21)\end{array}$ & 98.3 & 15.6 & 14.3 & 85.90 & $(5.33,0.33)$ \\
\hline & $\begin{array}{l}\text { No }(n=8, \\
N=58)\end{array}$ & 90.4 & 0.0 & 6.7 & 88.06 & $(4.95,0.44)$ \\
\hline & $\begin{array}{l}\text { Total }(\mathrm{n}=11, \\
\mathrm{N}=79)\end{array}$ & 92.5 & 4.2 & 8.7 & 87.48 & $(5.05,0.45)$ \\
\hline \multirow[t]{3}{*}{ INT } & $\begin{array}{l}\text { Yes }(n=8, \\
N=54)\end{array}$ & 125.5 & 24.9 & 11.8 & 87.53 & $(5.17,0.34)$ \\
\hline & $\begin{array}{l}\text { No }(n=26, \\
N=222)\end{array}$ & 87.4 & 0.0 & 7.5 & 84.16 & $(5.00,0.41)$ \\
\hline & $\begin{array}{l}\text { Total }(\mathrm{n}=32, \\
\mathrm{N}=276)\end{array}$ & 94.9 & 4.9 & 8.3 & 84.82 & $(5.03,0.40)$ \\
\hline \multirow[t]{3}{*}{ Total } & $\begin{array}{l}\text { Yes }(n=12 \\
N=95)\end{array}$ & 128.9 & 31.0 & 11.8 & 87.72 & $(5.07,0.35)$ \\
\hline & $\begin{array}{l}\text { No }(n=31 \\
N=280)\end{array}$ & 84.3 & 0.0 & 8.0 & 84.89 & $(4.99,0.42)$ \\
\hline & $\begin{array}{l}\text { Total }(n=41, \\
N=375)\end{array}$ & 95.6 & 7.9 & 9.0 & 85.61 & $(5.01,0.40)$ \\
\hline
\end{tabular}

$A B C$, adventure-based counseling; VTS, volunteer training and service; WORK, work related; INT, interest-enhancement. n, Number of projects; N, Number of implementers; N/A, not applicable. ${ }^{a}$ For each of the four program approach variables (i.e. ABC, VTS, WORK, and INT), if the corresponding element was adopted in the program, the variable was coded as " 1 "; otherwise, it was coded as "0". Almost all programs adopted a combination of two or more elements.

Table 2: Mean, standard deviations, Cronbach's $\alpha$ 's, and mean of inter-item correlations among the variables by grade.

\begin{tabular}{|c|c|c|c|c|c|c|c|c|}
\hline & \multicolumn{2}{|r|}{ Grade 7} & \multicolumn{2}{|r|}{ Grade 8} & \multicolumn{2}{|r|}{ Grade 9} & \multicolumn{2}{|r|}{ Overal } \\
\hline & $M(S D)$ & $\alpha\left(\right.$ Mean $\left.^{a}\right)$ & $M(S D)$ & $\alpha\left(\right.$ Mean $\left.^{\mathrm{a}}\right)$ & $M(S D)$ & $\alpha\left(\right.$ Mean $\left.^{\mathrm{a}}\right)$ & $M(S D)$ & $\alpha\left(\right.$ Mean $\left.^{a}\right)$ \\
\hline Program content (eight items) & $5.07(0.40)$ & $0.88(0.49)$ & $5.01(0.47)$ & $0.89(0.50)$ & $5.08(0.50)$ & $0.90(0.53)$ & $5.07(0.44)$ & $0.89(0.51)$ \\
\hline Program implementers (eight items) & $5.04(0.44)$ & $0.89(0.52)$ & $5.12(0.47)$ & $0.92(0.58)$ & $5.10(0.45)$ & $0.89(0.49)$ & $5.09(0.45)$ & $0.90(0.53)$ \\
\hline Program benefits (eight items) & $4.85(0.51)$ & $0.91(0.55)$ & $4.86(0.52)$ & $0.91(0.55)$ & $4.93(0.58)$ & $0.90(0.54)$ & $4.88(0.53)$ & $0.91(0.55)$ \\
\hline Total effectiveness ( 24 items) & $4.98(0.38)$ & $0.94(0.39)$ & $4.99(0.40)$ & $0.94(0.38)$ & $5.01(0.43)$ & $0.94(0.40)$ & $5.01(0.40)$ & $0.94(0.40)$ \\
\hline
\end{tabular}

aMean: inter-item correlations.

I conducted" (99.5\%). Almost all (99.7\%) of the implementers "would recommend others who have similar needs to participate in this program". As demonstrated in Table 4, implementers were also very satisfied with their own performance in the activities. Nearly all implementers indicated that "my working skills were good" (99.7\%) and "my attitudes were good" (99.7\%). They were "satisfied with my performance on the whole" (99.7\%). Furthermore, implementers believed that the Tier 2 Programs had benefits for the participants (Table 5). They indicated that the program "enhanced the participants to grow" (98.4\%) and "participants have positive changes after joining the 
Table 3: Summary of the views of program implementers on the program.

\begin{tabular}{|c|c|c|c|c|c|c|c|c|}
\hline & \multicolumn{8}{|c|}{ Implementers with positive responses (rating 4-6) across different grades } \\
\hline & \multicolumn{2}{|c|}{ Grade 7} & \multicolumn{2}{|c|}{ Grade 8} & \multicolumn{2}{|c|}{ Grade 9} & \multicolumn{2}{|c|}{ Overall } \\
\hline & $\mathbf{N}$ & $\%$ & $\mathbf{N}$ & $\%$ & $\mathbf{N}$ & $\%$ & $\mathbf{N}$ & $\%$ \\
\hline 1. The activities were well planned & 207 & 98.1 & 87 & 100 & 68 & 100 & 371 & 98.9 \\
\hline 2. The quality of the service was high & 208 & 98.6 & 87 & 100 & 68 & 100 & 372 & 99.2 \\
\hline 3. The service provided could meet the participants' needs & 209 & 99.1 & 85 & 97.7 & 67 & 98.5 & 370 & 98.7 \\
\hline $\begin{array}{l}\text { 4. The service delivered could achieve the planned } \\
\text { objectives }\end{array}$ & 208 & 98.6 & 85 & 97.7 & 66 & 97.1 & 368 & 98.1 \\
\hline 5. I could provide the service participants wanted & 209 & 99.1 & 84 & 96.6 & 67 & 98.5 & 369 & 98.4 \\
\hline $\begin{array}{l}\text { 6. The program provided many chances for participants to } \\
\text { interact with each other }\end{array}$ & 210 & 99.5 & 86 & 98.9 & 66 & 97.1 & 371 & 98.9 \\
\hline $\begin{array}{l}\text { 7. I would recommend others who have similar needs to } \\
\text { participate in this program }\end{array}$ & 210 & 99.5 & 87 & 100 & 68 & 100 & 374 & 99.7 \\
\hline $\begin{array}{l}\text { 8. On the whole, I am satisfied with the service I } \\
\text { conducted }\end{array}$ & 209 & 99.1 & 87 & 100 & 68 & 100 & 373 & 99.5 \\
\hline
\end{tabular}

All items are on a 6-point Likert scale with $1=$ strongly disagree, 2 = disagree, $3=$ slightly disagree, $4=$ slightly agree, $5=$ agree, $6=$ strongly agree. Only respondents with positive responses (Options 4-6) are shown in the table.

Table 4: Summary of the views of program implementers on their own performance.

\begin{tabular}{|c|c|c|c|c|c|c|c|c|}
\hline & \multicolumn{8}{|c|}{ Implementers with positive responses (rating 4-6) across different grades } \\
\hline & \multicolumn{2}{|c|}{ Grade 7} & \multicolumn{2}{|c|}{ Grade 8} & \multicolumn{2}{|c|}{ Grade 9} & \multicolumn{2}{|c|}{ Overal } \\
\hline & $\mathbf{N}$ & $\%$ & $\mathbf{N}$ & $\%$ & $\mathbf{N}$ & $\%$ & $\mathbf{N}$ & $\%$ \\
\hline 1. I used my professional knowledge & 209 & 99.1 & 87 & 100 & 68 & 100 & 373 & 99.5 \\
\hline 2. My working skills were good & 210 & 99.5 & 87 & 100 & 68 & 100 & 374 & 99.7 \\
\hline 3. I was well prepared for the program & 206 & 97.6 & 85 & 97.7 & 68 & 100 & 368 & 98.1 \\
\hline 4. I understood the needs of the participants & 208 & 98.6 & 85 & 97.7 & 66 & 97.1 & 368 & 98.1 \\
\hline 5. I cared about the participants & 209 & 99.1 & 87 & 100 & 68 & 100 & 373 & 99.5 \\
\hline 6. My attitudes were good & 210 & 99.5 & 87 & 100 & 68 & 100 & 374 & 99.7 \\
\hline 7. I had much interaction with participants & 208 & 98.6 & 87 & 100 & 67 & 98.5 & 371 & 98.9 \\
\hline 8. On the whole, I am satisfied with my performance & 210 & 99.5 & 87 & 100 & 68 & 100 & 374 & 99.7 \\
\hline
\end{tabular}

All items are on a 6 -point Likert scale with $1=$ strongly disagree, 2 = disagree, $3=$ slightly disagree, $4=$ slightly agree, $5=$ agree, $6=$ strongly agree. Only respondents with positive responses (Options 4-6) are shown in the table.

program" (98.1\%). They also believed that in the future, "the participants would join similar programs if needed" (98.4\%). Therefore, the Hypotheses 1a, 1b, and 1c in the present study were well supported.

Regarding the associations among satisfaction ratings on program content, implementer quality, and program benefits, correlation analyses were conducted. As expected, significant positive correlations among program content, implementer quality, and perceived program benefits were found, with correlation coefficients ranging from 0.52 to $0.68(\mathrm{p}<0.001)$. The results supported Hypotheses 2a, 2b, and 2c. According to the results of multiple regression analyses, implementers' ratings on program effectiveness were significantly predicted by their satisfaction ratings on program content $(\beta=0.56, p<0.001)$ and the ratings on their own performance $(\beta=0.21, \mathrm{p}<0.001)$. The positive inter-correlations and predictive relationships were also consistent across grades as indicated in Tables 6 and 7. Therefore, Hypotheses $2 \mathrm{~d}$ and $2 \mathrm{e}$ were also supported.

To explore the differences among implementers across grades when evaluating the program from three aspects, MANOVAs were conducted. According to the findings in Table 8, no significant grade differences were found among implementers when they were rating their satisfaction with program content $[F$ (2356) $\left.=0.42, \mathrm{p}=0.66, \eta_{p}{ }^{2}=0.002\right]$, their own performance [F $\left.(2356)=1.00, \mathrm{p}=0.37, \eta_{p}{ }^{2}=0.006\right]$, program benefits $\left[F(2356)=0.54, \mathrm{p}=0.58, \eta_{p}{ }^{2}=0.003\right]$, as well as the overall program effectiveness $\left[F(2356)=0.14, \mathrm{p}=0.87, \eta_{p}{ }^{2}=0.001\right]$. 
Table 5: Summary of the program implementers' perceptions of the benefits of the Tier 2 Program.

\begin{tabular}{|c|c|c|c|c|c|c|c|c|}
\hline & \multicolumn{8}{|c|}{ Participants with positive responses (rating 4-6) across different grades } \\
\hline & \multicolumn{2}{|c|}{ Grade 7} & \multicolumn{2}{|c|}{ Grade 8} & \multicolumn{2}{|c|}{ Grade 9} & \multicolumn{2}{|c|}{ Overal } \\
\hline & $\mathbf{N}$ & $\%$ & $\mathbf{N}$ & $\%$ & $\mathbf{N}$ & $\%$ & $\mathbf{N}$ & $\%$ \\
\hline 1. The program helped the participants a lot & 208 & 98.6 & 84 & 96.6 & 64 & 94.1 & 365 & 97.3 \\
\hline 2. The program enhanced the participants to grow & 209 & 99.1 & 87 & 100 & 64 & 94.1 & 369 & 98.4 \\
\hline $\begin{array}{l}\text { 3. In the future, the participants would join similar } \\
\text { program(s) if needed }\end{array}$ & 209 & 99.1 & 87 & 100 & 64 & 94.1 & 369 & 98.4 \\
\hline $\begin{array}{l}\text { 4. Participants have learned how to help themselves } \\
\text { through participating in the program }\end{array}$ & 208 & 98.6 & 85 & 97.7 & 63 & 92.6 & 365 & 97.3 \\
\hline $\begin{array}{l}\text { 5. Participants have positive change(s) after joining } \\
\text { the program }\end{array}$ & 209 & 99.1 & 86 & 98.9 & 64 & 94.1 & 368 & 98.1 \\
\hline $\begin{array}{l}\text { 6. Participants have learned how to solve their own } \\
\text { problems through participating in the program }\end{array}$ & 209 & 99.1 & 85 & 97.7 & 64 & 94.1 & 367 & 97.9 \\
\hline $\begin{array}{l}\text { 7. Compared with before joining this program, } \\
\text { participants' behavior has become better }\end{array}$ & 205 & 97.2 & 84 & 96.6 & 61 & 89.7 & 359 & 95.7 \\
\hline $\begin{array}{l}\text { 8. Those who know the participants agree that this } \\
\text { program has induced positive changes in them }\end{array}$ & 205 & 97.2 & 84 & 96.6 & 64 & 94.1 & 362 & 96.5 \\
\hline
\end{tabular}

All items are on a 6-point Likert scale with $1=$ strongly disagree, 2 =disagree, $3=$ slightly disagree, $4=$ slightly agree, $5=$ agree, $6=$ strongly agree. Only respondents with positive responses (Options 4-6) are shown in the table.

Table 6: Correlation coefficients on the relationship between program components and program benefits by grade.

\begin{tabular}{|c|c|c|c|c|c|c|c|c|}
\hline \multirow[t]{2}{*}{ Variables } & \multicolumn{2}{|c|}{ Grade 7} & \multicolumn{2}{|c|}{ Grade 8} & \multicolumn{2}{|c|}{ Grade 9} & \multicolumn{2}{|r|}{ Total } \\
\hline & 2 & 3 & 2 & 3 & 2 & 3 & 2 & 3 \\
\hline 1. Program content & $0.58^{\mathrm{a}}$ & $0.64^{\mathrm{a}}$ & $0.43^{\mathrm{a}}$ & $0.70^{\mathrm{a}}$ & $0.59^{\mathrm{a}}$ & $0.70^{\mathrm{a}}$ & $0.56^{\mathrm{a}}$ & $0.68^{\mathrm{a}}$ \\
\hline 2. Program implementers & - & $0.51^{\mathrm{a}}$ & - & $0.45^{\mathrm{a}}$ & - & $0.56^{\mathrm{a}}$ & - & $0.52^{\mathrm{a}}$ \\
\hline 3. Program benefits & - & - & - & - & - & - & - & - \\
\hline
\end{tabular}

${ }^{\mathrm{a}} \mathrm{p}<0.001$

Table 7: Multiple regression analyses predicting program benefits by grade.

\begin{tabular}{|c|c|c|c|c|}
\hline & \multicolumn{2}{|r|}{ Predictors } & \multicolumn{2}{|r|}{ Mode } \\
\hline & Program content & Program implementers & & \\
\hline & $\beta^{\mathrm{a}}$ & $\beta^{\mathrm{a}}$ & $R$ & $R^{2}$ \\
\hline Grade 7 & $0.52^{d}$ & $0.20^{c}$ & 0.66 & 0.43 \\
\hline Grade 8 & $0.62^{d}$ & $0.19^{b}$ & 0.72 & 0.52 \\
\hline Grade 9 & $0.57^{d}$ & $0.24^{b}$ & 0.73 & 0.54 \\
\hline Overall & $0.56^{d}$ & $0.21^{d}$ & 0.70 & 0.49 \\
\hline
\end{tabular}

${ }^{\text {aS }}$ Standardized coefficients; ${ }^{\mathrm{b}} \mathrm{p}<0.05 ;{ }^{\mathrm{c}} \mathrm{p}<0.01 ;{ }^{\mathrm{d}} \mathrm{p}<0.001$.

Hence, Hypothesis 3 that there would be grade differences among program implementers' satisfaction ratings was not supported in the present study.

To examine the impact of parental involvement and the delivery approaches, a series of ANOVAs were conducted with the three subjective outcome evaluation aspects (i.e. program content, implementer performance, and program benefits) as dependent variables, and the four program approaches (ABC, VTS, WORK, and INT) as well as parental involvement as independent variables. As demonstrated in Table 9, results revealed that programs adopting the "INT" element received higher satisfaction ratings than did the programs without the "INT" element in terms of program content $[F(1359)=5.88$, $\left.\mathrm{p}=0.016, \quad \eta_{p}^{2}=0.016\right]$, implementer performance $[F$ $\left.(1359)=7.71, \mathrm{p}=0.006, \eta_{p}{ }^{2}=0.021\right]$, and program benefits $\left[F(1359)=13.02, \mathrm{p}<0.001, \eta_{p}{ }^{2}=0.034\right]$. No main effects of the other three elements ("ABC", "VTS", and "WORK") were found. Hence, Hypothesis 4 was partially supported. Regarding the influence of parental involvement, no main effect was found (Wilk's $\Lambda=0.99, F(1359)=0.86-1.53$, $\left.\mathrm{p}=0.112-0.354, \eta_{p}{ }^{2}=0.002-0.007\right)$.

The findings suggested that there is a need to look at the related interaction effects. It was found that parental involvement and the "WORK" element had a significant two-way interaction effect on program implementers (Wilk's $\left.\Lambda=0.99, F(1359)=7.67, \mathrm{p}=0.006, \eta_{p}{ }^{2}=0.021\right)$. A 
Table 8: Comparisons of the program evaluations by implementers in different grade levels.

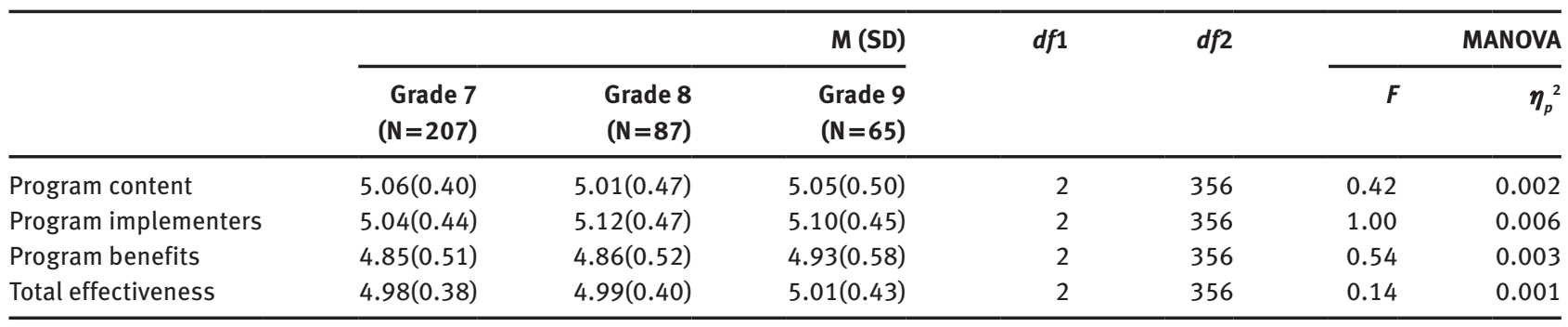

further simple effect analysis (Table 10 and Figure 1) revealed that for programs with "WORK" element, parental involvement significantly raised implementers' satisfaction ratings on their own performance $(\mathrm{M}=4.98, \mathrm{SD}=0.47$; $\left.\mathrm{M}=5.42, \mathrm{SD}=0.35 ; F(1359)=14.66, \mathrm{p}<0.001, \eta_{p}{ }^{2}=0.167\right)$. Therefore, hypothesis 5 was partially supported.

\section{Discussion}

Adolescents' problematic behaviors may result in academic failure, physical or psychological harms, and even social issues [1, 2]. The Project P.A.T.H.S. is a strength-based youth development program that is tailored to help adolescents in Hong Kong from an ecological perspective [5]. This article examined the effectiveness of the community-based Tier 2 Program of the Project P.A.T.H.S. implemented in the year 2015 from the views of 375 implementers.

According to the present findings based on subjective outcome evaluation, the program was successfully implemented as expected. It has received quite a positive evaluation from the implementers in the aspects of perceived program content, self-perceived performance, and perceived program benefits. The overall perceived program effectiveness ranged from 3.46 to 6.00 on a 6-point Likert scale. One of the big concerns when designing the community-based Tier 2 Program was whether it could be as effective as the school-based programs. The findings in the present study solidly supported the effectiveness of the community-based programs. It is delightful to observe the successful outcomes due to a valuable collaboration between social workers in NGOs and teachers in schools. Meanwhile, no grade differences were found in the subjective outcome evaluation results. The findings were in agreement with Shek, $\mathrm{Ng}$, and Law's study [27]. One possible explanation could be that Tier 2 Programs conducted in three grades were equally effective and that implementers of all grades were equally satisfied with their own performance.

In line with the findings of previous studies [21, 27], the satisfaction ratings of both program content and implementer performance positively predicted perceived program benefits. The prediction effects were consistent across grades. These findings imply that in order to promote the holistic development of adolescents in different areas (such as emotional competence, prosocial norms, bonding, and self-efficacy), the program content should be well-designed and the implementers should be well-trained and wholehearted. Shek and colleagues [51] proposed that factors influencing the program quality could be concluded as 5 "P"s (policy, program, people, place, and process). The findings being presented echo the 5P model by identifying the importance of "program" and "people". In future studies, the other three factors could also be considered.

Different types of delivery approaches were used in the community-based Tier 2 Programs. Previous studies indicated that students had the highest preference for the ABC and VTS approaches $[25,43]$. Owing to the successful implementation experience, almost every project incorporated the ABC and/or VTS element(s) during 2015. However, also due to the over-widened gap of the number of participants (355 implementers were in programs with the "ABC" element while only 20 were not; 342 implementers were in programs with the "VTS" element while only 33 were not), the positive influence of adopting ABC and VTS approach on the program effectiveness was not successfully found in the present study. On the other hand, adopting "INT" approach was found to have positive influences on implementers' satisfaction ratings in program content, implementer quality, and program benefits, which are new findings in evaluation studies for the P.A.T.H.S. Project. INT activities motivate adolescents to learn and practice with enthusiasm [46]. In that way, implementers would also be activated and encouraged to make the activities more interesting and interactive. In the future, further investigation of the impacts of the combination of different approaches should be considered.

Although no main effect was found to demonstrate the positive influence of parental involvement, the interaction effect between parental involvement and "WORK" 
Table 9: The impacts of parental involvement and delivery approaches on program effectiveness evaluated by implementers.

\begin{tabular}{|c|c|c|c|c|c|c|c|}
\hline \multirow[t]{2}{*}{ Dependent variables } & \multirow[t]{2}{*}{ Independent variables } & \multicolumn{2}{|r|}{ Yes } & \multicolumn{2}{|r|}{ No } & \multirow[t]{2}{*}{$\boldsymbol{F}$} & \multirow[t]{2}{*}{$\boldsymbol{\eta}_{p}^{2}$} \\
\hline & & $\mathbf{N}$ & $(M, S D)$ & $\mathbf{N}$ & $(M, S D)$ & & \\
\hline \multirow[t]{10}{*}{ Program content } & Main effects & & & & & & \\
\hline & Parental involvement & 94 & $5.12(0.36)$ & 274 & $5.04(0.46)$ & 1.53 & 0.004 \\
\hline & $A B C$ & 348 & $5.08(0.44)$ & 20 & $4.96(0.54)$ & 1.36 & 0.004 \\
\hline & VTS & 336 & $5.07(0.45)$ & 32 & $5.05(0.40)$ & 0.11 & 0.000 \\
\hline & WORK & 75 & $5.11(0.48)$ & 293 & $5.06(0.43)$ & 0.20 & 0.001 \\
\hline & INT & 269 & $5.10(0.47)$ & 99 & $4.99(0.43)$ & $5.88^{\mathrm{a}}$ & 0.016 \\
\hline & Interaction effects ${ }^{d}$ & & & & & & \\
\hline & Parental involvement ${ }^{\mathrm{a}}$ VTS & & & & & 0.07 & 0.000 \\
\hline & Parental involvement ${ }^{\mathrm{a}}$ WORK & & & & & 1.69 & 0.005 \\
\hline & Parental involvement ${ }^{\mathrm{a}}$ INT & & & & & 0.98 & 0.003 \\
\hline \multirow[t]{10}{*}{ Program implementers } & Main effects & & & & & & \\
\hline & Parental involvement & 94 & $5.14(0.37)$ & 274 & $5.06(0.47)$ & 2.54 & 0.007 \\
\hline & $\mathrm{ABC}$ & 348 & $5.09(0.44)$ & 20 & $5.06(0.64)$ & 0.79 & 0.002 \\
\hline & VTS & 336 & $5.08(0.45)$ & 32 & $5.13(0.47)$ & 0.68 & 0.002 \\
\hline & WORK & 75 & $5.13(0.49)$ & 293 & $5.07(0.44)$ & 0.32 & 0.001 \\
\hline & INT & 269 & $5.11(0.46)$ & 99 & $5.00(0.43)$ & $7.71^{\mathrm{b}}$ & 0.021 \\
\hline & Interaction effects ${ }^{1}$ & & & & & & \\
\hline & Parental involvement ${ }^{\mathrm{a}}$ VTS & & & & & 0.01 & 0.000 \\
\hline & Parental involvement ${ }^{\mathrm{a}}$ WORK & & & & & $7.67^{b}$ & 0.021 \\
\hline & Parental involvement ${ }^{\mathrm{a}}$ INT & & & & & 0.36 & 0.001 \\
\hline \multirow[t]{10}{*}{ Program benefits } & Main effects & & & & & & \\
\hline & Parental involvement & 94 & $4.96(0.45)$ & 274 & $4.85(0.55)$ & 0.86 & 0.002 \\
\hline & $A B C$ & 348 & $4.88(0.52)$ & 20 & $4.89(0.70)$ & 0.72 & 0.002 \\
\hline & VTS & 336 & $4.87(0.53)$ & 32 & $4.95(0.53)$ & 0.27 & 0.001 \\
\hline & WORK & 75 & $4.98(0.55)$ & 293 & $4.86(0.52)$ & 2.35 & 0.007 \\
\hline & INT & 269 & $5.09(0.53)$ & 99 & $4.83(0.51)$ & $13.02^{c}$ & 0.035 \\
\hline & Interaction effects ${ }^{d}$ & & & & & & \\
\hline & Parental involvement ${ }^{\mathrm{a}}$ VTS & & & & & 0.10 & 0.000 \\
\hline & Parental involvement ${ }^{\mathrm{a}}$ WORK & & & & & 3.50 & 0.010 \\
\hline & Parental involvement ${ }^{\mathrm{a}}$ INT & & & & & 0.50 & 0.001 \\
\hline
\end{tabular}

$A B C$, adventure-based counseling; VTS, volunteer training and service; WORK, work related; INT, interest-enhancement. ${ }^{\mathrm{a}} \mathrm{p}<0.05$; ${ }^{\mathrm{b}} \mathrm{p}<0.01$; ${ }^{c} p<0.001$; ${ }^{d}$ There are no interaction effects between parental involvement and the $A B C$ approach as all programs that involved parent(s) adopted the $A B C$ activities.

Table 10: Simple effect analysis of the interactions between "WORK" element and "parental involvement" on perceived implementer performance.

\begin{tabular}{|c|c|c|c|c|c|c|}
\hline & \multicolumn{4}{|c|}{ Parental involvement } & \multirow[t]{3}{*}{$\boldsymbol{F}$} & \multirow[t]{3}{*}{$\boldsymbol{\eta}_{p}{ }^{2}$} \\
\hline & \multicolumn{2}{|r|}{ Yes } & \multicolumn{2}{|r|}{ No } & & \\
\hline & $\mathbf{N}$ & $(M, S D)$ & $\mathbf{N}$ & $(M, S D)$ & & \\
\hline \multicolumn{7}{|l|}{ WORK } \\
\hline Yes & 20 & $(5.42,0.35)$ & 55 & $(4.98,0.47)$ & $14.66^{\mathrm{a}}$ & 0.167 \\
\hline No & 74 & $(5.06,0.34)$ & 219 & $(5.08,0.47)$ & 0.159 & 0.001 \\
\hline
\end{tabular}

${ }^{\mathrm{a}} \mathrm{p}<0.001$.

element partially supported the benefits of parental involvement in youth development programs. A previous study found that students preferred the programs involving only students more than the programs also involving parents [52]. It is understandable that implementers valued the potential benefits for students more, while participated students preferred more relaxing experiences without parents' restrictions. Involving parents in "WORK" activities not only inspires parents to help kids' career development but also contributes to the affectional ties within families. From the ecological perspective, supportive parents and teachers could provide protective factors for the adolescents at a community level [12].

Despite the above-mentioned contributions, the present study has several limitations. First, a fundamental concern for subjective outcome evaluation is the social desirability and self-serving bias because most of the responses were quite positive. It is human nature that individuals, including the program implementers, tend to perceive own performance as positive [53]. Therefore, a combination of both subjective and objective outcome evaluations from the perspectives of other stakeholders would be 


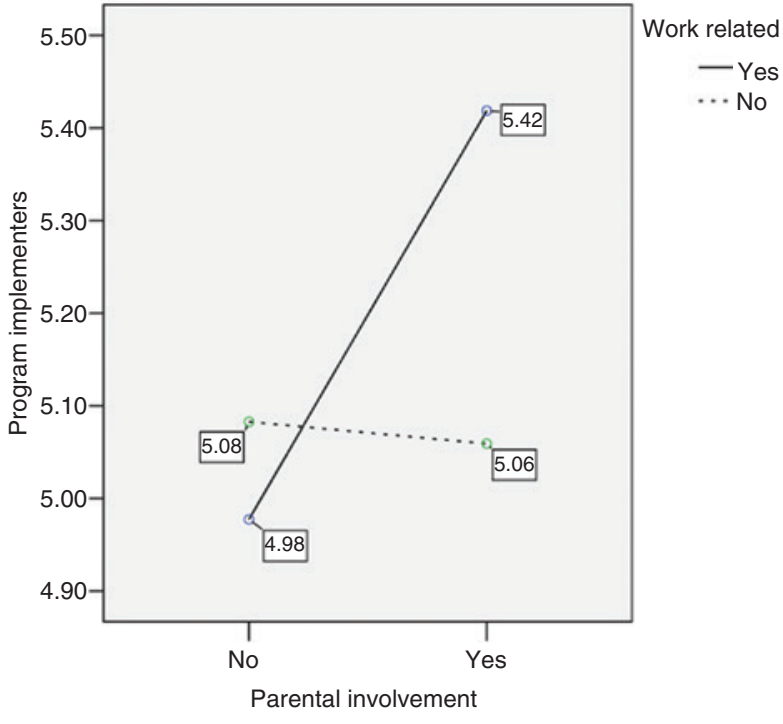

Figure 1: Simple effect analysis of the interactions between "WORK" element and "parental involvement" on perceived implementer performance.

necessary. Second, as the community-based Tier 2 Program was mainly developed and implemented by NGO social workers, it would be difficult for research team members to master the details of the implementation process. Hence, qualitative evaluation measures, such as focus group and individual interviews, would be helpful to better evaluate and improve the programs. Third, a larger sample size would substantially enhance the generalizability of the findings in the current study. For example, the efficiency of parental involvement could not be well examined without sufficient participants. Future evaluating studies could also consider their voices. Notwithstanding these limitations, the current study provided evidence for the success and effectiveness of the community-based Tier 2 Program of the P.A.T.H.S. Project. It also shed light on the future improvement of positive youth development programs.

Acknowledgments: The preparation for this paper and the Project P.A.T.H.S. were financially supported by The Hong Kong Jockey Club Charities Trust.

\section{References}

1. Omer H, Lebowitz ER. Nonviolent resistance: Helping caregivers reduce problematic behaviors in children and adolescents. J Marital Fam Ther 2016;42:688-700.

2. Donovan JE, Jessor R. Structure of problem behavior in adolescence and young adulthood. J Consult Clin Psychol 1985;53:890-904.
3. Shek DT. Adolescent developmental issues in Hong Kong: relevance to positive youth development programs in Hong Kong. Int J Adolesc Med Health 2006;18:341-54.

4. Ho SM, Lee TM. Computer usage and its relationship with adolescent lifestyle in Hong Kong. Adolesc Health 2001;29:258-66.

5. Shek DT, Keung Ma H, Sun RC. A brief overview of adolescent developmental problems in Hong Kong. ScientificWorldJ 2011;11:2243-56.

6. Gil AG, Wagner EF, Tubman JG. Culturally sensitive substance abuse intervention for Hispanic and African American adolescents: empirical examples from the Alcohol Treatment Targeting Adolescents in Need (ATTAIN) Project. Addiction 2004;99(s2):140-50.

7. Botvin GJ, Baker E, Filazzola AD, Botvin EM. A cognitive-behavioral approach to substance abuse prevention: one-year follow-up. Addict Behav 1990;15:47-63.

8. Sosin MR, Bruni M, Reidy M. Paths and impacts in the progressive independence model: a homelessness and substance abuse intervention in Chicago. J Addict Dis 1996;14:1-20.

9. Smith EJ. The strength-based counseling model. Couns Psychol 2006;34:13-79.

10. Martin S. Building resilience from the grassroots up. Monit Psychol 2002;33:52-3.

11. Jessor R, Turbin MS, Costa FM, Dong Q, Zhang H, Wang C. Adolescent problem behavior in China and the United States: a cross-national study of psychosocial protective factors. J Res Adolesc 2003;13:329-60.

12. Shek DT, Leung JT. Adolescent developmental issues in Hong Kong: phenomena and implications for youth service. In: Shek DT, Sun RC, eds. Development and evaluation of positive adolescent training through holistic social programs (P.A.T.H.S.). Singapore: Springer, 2013:1-13.

13. Shek DT, Sun RC. The Project PATHS in Hong Kong: development, training, implementation, and evaluation. J Pediatr Adolesc Gynecol 2013;26:S2-9.

14. Law BM, Shek DT. Process evaluation of a positive youth development program: Project P.A.T.H.S. Res Soc Work 2011;21:539-48.

15. Scheirer MA. Designing and using process evaluation. Handb Pract Program Eval 1994;5:40-68.

16. Shek DT, Ma HK, Sun RC. Interim evaluation of the Tier 1 Program (Secondary 1 Curriculum) of the Project PATHS: first year of the full implementation phase. ScientificWorldJ 2008;8:47-60.

17. Shek DT, Sun RC, Kan VW. Full implementation of the Secondary 1 program of Project PATHS: observations based on the cowalker scheme. ScientificWorldJ 2009;9:982-91.

18. Schalock RL. Outcome-based evaluation. NY: Springer Science \& Business Media, 2001.

19. Shek DT, Yu L. Subjective outcome evaluation of the project PATHS (extension phase) based on the perspective of program implementer. ScientificWorldJ 2012;2012:1-8.

20. Shek DT, Yu L, Ho VY. Subjective outcome evaluation and factors related to perceived effectiveness of the Project PATHS in Hong Kong. ScientificWorldJ 2012;2012: Article 490290, 10 pages. DOI: $10.1100 / 2012 / 490290$.

21. Shek DT, Siu AM, Lee TY. Subjective outcome evaluation of the Project PATHS: findings based on the perspective of the program implementers. ScientificWorldJ 2007;7:195-203.

22. Hofferth SL. The effects of programs and policies on adolescent pregnancy and childbearing. In Hofferth S, Yhes C, eds. Risking the future: adolescent sexuality, pregnancy and 
childbearing. Washington, DC, US: Department of Education, 1987:207-63.

23. Franklin C, Corcoran J. Preventing adolescent pregnancy: a review of programs and practices. Soc Work 2000;45:40-52.

24. Shek DT, Wu FK. The Project PATHS in Hong Kong: work done and lessons learned in a decade. J Pediatr Adolesc Gynecol 2016;29:S3-11.

25. Shek DT, Zhu XQ, Wu FK. Subjective outcome evaluation of the community-based program of the P.A.T.H.S. project in Hong Kong. Int J Child Adolesc Health, in press.

26. Shek DT, Law MY. Evaluation of programs for adolescents with greater psychosocial needs: community-based Project PATHS in Hong Kong. Int J Adolesc Med Health, 2016. Epub ahead of print 14 Jun 2016. DOI: 10.1515/ijamh-2017-3004.

27. Shek DT, Ng CM, Law MY. Positive youth development programs for adolescents with greater psychosocial needs: evaluation based on program implementers. Int J Child Adolesc Health, 2016. Epub ahead of print 14 Jun 2016. DOI: 10.1515/ijamh-2017-3005.

28. Shek DT, Lin L. Project P.A.T.H.S. for adolescents with greater psychosocial needs: evaluation based on the program implementers. Int J Child Adolesc Health, in press.

29. Forman SG, Olin SS, Hoagwood KE, Crowe M, Saka N. Evidencebased interventions in schools: developers' views of implementation barriers and facilitators. Sch Ment Health 2009;1:26-36.

30. Taut S. What have we learned about stakeholder involvement in program evaluation? Stud Educ Eval 2008;34:224-30.

31. Cousins JB, Whitmore E. Framing participatory evaluation. New Dir Eval 1998;1998:5-23.

32. Greene JC. Stakeholder participation in evaluation design: is it worth the effort?. Eval Program Plann 1987;10:379-94.

33. Sun RC, Shek DT. Perceived program qualities and outcomes of a youth program in Hong Kong: based on the views of the workers. J Pediatr Adolesc Gynecol 2014;27:S10-6.

34. House ER. Stakeholder bias. New Dir Eval 2003;2003:53-6.

35. Winefield HR, Barlow, JA. Client and worker satisfaction in a child protection agency. Child Abuse Negl 1995;19:897-905.

36. Glass JS, Shoffner MF. Adventure-based counseling in schools. Prof Sch Couns 2001;5:42-8.

37. Moote Jr GT, Wodarski JS. The acquistion of life skills through adventure-based activities and programs: a review of the literature. Adolescence 1997;32:143-67.

38. Harris PM, Mealy L, Matthews H, Lucas R, Moczygemba M. A wilderness challenge program as correctional treatment. J Offender Rehabil 1993;19:149-64.
39. Koperski H, Tucker AR, Lung DM, Gass MA. The impact of community based adventure therapy on stress and coping skills in adults. The Practitioner Scholar: J Couns Prof Psychol 2015;4:1-16.

40. Hinduja S, Patchin JW. Cyberbullying: neither an epidemic nor a rarity. Eur J Dev Psychol 2012;9:539-43.

41. Penner LA. Volunteerism and social problems: making things better or worse?. J Soc Issues 2004;60:645-66.

42. Omoto AM, Snyder M. Sustained helping without obligation: motivation, longevity of service, and perceived attitude change among AIDS volunteers. J Pers Soc Psychol 1995;68:671-86.

43. Allen JP, Kuperminc G, Philliber S, Herre K. Programmatic prevention of adolescent problem behaviors: the role of autonomy, relatedness, and volunteer service in the Teen Outreach Program. Am J Community Psychol 1994;22:595-615.

44. Whiston SC, Quinby RF. Review of school counseling outcome research. Psychol Sch 2009;46:267-72.

45. Eccles JS, Barber BL. Student council, volunteering, basketball, or marching band what kind of extracurricular involvement matters? J Adolesc Res 1999;14:10-43.

46. Kobayashi M, Lockee B. Evidence-based approaches for selfregulated learning. Educ 2008;5:32-44.

47. Epstein JL, Sanders MG. Prospects for change: Preparing educators for school, family, and community partnerships. Peabody J Educ 2006;81:81-120.

48. Hoover-Dempsey KV, Walker JM, Jones KP, Reed RP. Teachers involving parents (TIP): results of an in-service teacher education program for enhancing parental involvement. Teach Teach Educ 2002;18:843-67.

49. Zellman GL, Waterman JM. Understanding the impact of parent school involvement on children's educational outcomes. J Educ Res 1998;91:370-80.

50. Hoover-Dempsey KV, Sandler HM. Parental involvement in children's education: why does it make a difference? Teach Coll Rec 1995;95:310-31.

51. Shek DT, Sun RC. Implementation of a positive youth development program in a Chinese context: the role of policy, program, people, process, and place. ScientificWorldJ 2008;8:980-96.

52. Shek DT, Tsui PF, Law MY. Evaluation of a school-based positive youth development program in Hong Kong: views of junior secondary school students. Int J Child Health Hum Dev 2015;8:167-79.

53. Miller DT, Ross M. Self-serving biases in the attribution of causality: fact or fiction? Psychol Bull 1975;82:213-25. 